\title{
“PERDI A GUARDA DO MEU FILHO!” A INTERFERÊNCIA DESSA QUESTÃo NO TRATAMENTO DE SAÚDE DAS MULHERES NA UNIPRAD
}

\author{
"I LOST MY CHILD'S GUARD!" THE INTERFERENCE OF THIS QUESTION \\ IN THE HEALTH CARE OF WOMEN IN UNIPRAD
}

\section{Laís Vargas Fernandes ${ }^{1}$ \\ Artemis Soares Viot Serra ${ }^{2}$}

\section{RESUMO}

Este trabalho teve como objetivo analisar o quanto a perda da guarda provisória ou definitiva dos filhos de mulheres usuárias de álcool e outras drogas atendidas em uma Unidade de Atenção aos Problemas Relacionados ao Álcool e outras Drogas, de um Instituto Universitário, no Rio de Janeiro, interfere no tratamento de saúde nesta área, além de procurar identificar a rede de acolhimento e suporte às mulheres; apresentar os aspectos legais que levam a perda da guarda e identificar quais são e como estão sendo aplicadas as políticas públicas para o enfrentamento e recuperação das mulheres usuárias de álcool e outras drogas. Estudo qualitativo, utilizando da entrevista semiestruturada como instrumento de coleta de dados e o referencial teórico de Laurence Bardin para análise dos dados. Percebeu-se que as políticas sociais nesta área ainda são focais, fragmentadas e tende a culpabilizar alguns segmentos da sociedade, como as mulheres.

PAlAVRAS-CHAVE: Álcool e Drogas. Perda da Guarda. Mulher. Políticas Públicas.

\section{ABSTRACT}

This study aimed to analyze how much the loss of temporary or permanent custody of women who use alcohol and other drugs met in a Care Unit to Problems Related to Alcohol and Other Drugs, a University Institute in Rio de Janeiro, interferes with the health treatment in this area, and try to identify the network host and support to women; serve the legal aspects that lead to loss of custody and identify what and how public policies for coping and recovery of women users of alcohol and other drugs are being applied. A qualitative study using semi-structured interviews as a data collection instrument and the theoretical framework of Laurence Bardin for data analysis. It has been

\footnotetext{
${ }^{1}$ Graduada pela Escola de Serviço Social da Universidade Federal do Rio de Janeiro, Especialista em Saúde da Mulher pelo Instituto de Atenção à Saúde São Francisco de Assis, Universidade Federal do Rio de Janeiro. Residente Multiprofissional em Serviço Social do Hospital Universitário Clementino Fraga Filho da UFRJ. Universidade Federal do Rio de Janeiro. Telefone: 5521 97577-2568. E-mail: vargaslais@yahoo.com.br

2 Mestre em Serviço Social pela Universidade Federal do Rio de Janeiro, assistente social da Unidade de Atenção aos Problemas Relacionados ao Álcool e outras Drogas do Instituto de Atenção à Saúde São Francisco de Assis HESFA/ UFRJ. E-mail: artemisviot@yahoo.com.br
} 


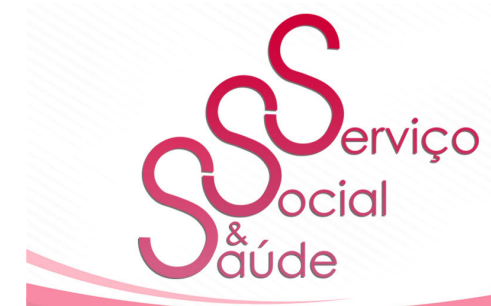

\section{ISSN 2446-5992}

(c) (i) (2)

doi: $10.20396 /$ sss.v0i0.00000000

realized that social policies in this area are still focal, fragmented and tend to blame some segments of society, such as women.

KEYWORDS: Alcohol and Drugs. Loss of Custody.Woman. Public Policy.

\section{INTRODUÇÃO}

Este trabalho foi vinculado ao Programa de Residência Multiprofissional em Saúde da Mulher do Instituto de Atenção à Saúde São Francisco de Assis (HESFA) da Universidade Federal do Rio de Janeiro (UFRJ), aprovado em Comitê de Ética e Pesquisa (CEP/EEAN) em Julho de 2014. Trata-se de um artigo que constituiu o trabalho de conclusão de curso de residência tornando-se uma parte da exigência para obtenção do título de especialista em Saúde da Mulher, apresentado e defendido em Fevereiro de 2015.

A pesquisa teve como objetivo analisar as implicações à saúde integral e os aspectos legais de mulheres mães usuárias de álcool e outras drogas que perderam a guarda provisória ou total de seus filhos, bem como, a rede de acolhimento e suporte que receberam ao enfrentarem este problema, além de refletir como estão sendo enfrentadas e aplicadas as políticas públicas na área de drogas.

Como procedimentos metodológicos foram realizados revisão bibliográfica, busca ativa em prontuários e entrevistas com mulheres adultas que perderam a guarda provisória ou total de seus filhos por realizarem uso de drogas e que foram encaminhadas pelo sistema judicial para tratamento.

Dentro desse contexto, utilizamos como cenário de pesquisa a Unidade de Atenção aos Problemas Relacionados ao Álcool e outras Drogas (UNIPRAD), do Instituto de Atenção à Saúde São Francisco de Assis (HESFA) da Universidade Federal do Rio de Janeiro (UFRJ) que atualmente é uma unidade de referência da área programática 1.0 (AP 1.0 $)^{3}$ do

\footnotetext{
${ }^{3} \mathrm{O}$ território da cidade do Rio de Janeiro é dividido em 10 áreas programáticas (AP's) e cada uma delas é composta por diversos bairros. A área programática 1.0 compreende os bairros do Centro e adjacências, a saber: Benfica, Caju, Catumbi, Centro, Cidade Nova, Estácio, Gamboa, Mangueira, Paquetá, Rio Comprido, Santa Teresa, Santo Cristo, São Cristóvão, Saúde e Vasco da Gama. Fonte: Coordenação de Vigilância Ambiental em Saúde do Rio de Janeiro.
} 


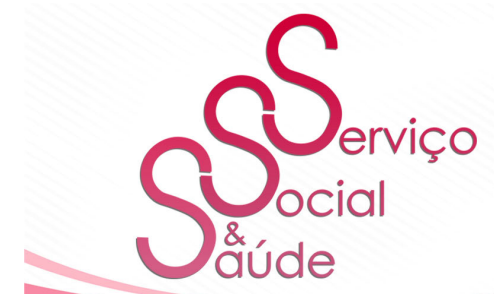

ISSN 2446-5992

(c) (i)(-)

doi: 10.20396/sss.v0i0.00000000

Centro do Município do Rio de Janeiro ao atendimento de usuários e familiares com problemas de consumo abusivo ou dependência de álcool e outras drogas e tem como objetivo integrar o ensino, a pesquisa e a assistência de forma a articular à prevenção ao tratamento, bem como, trabalhar a reabilitação psicossocial destes indivíduos. Atualmente, a equipe desta unidade é multiprofissional composta por Assistentes Sociais, Enfermeiros, Psicólogos, Psiquiatra, Terapeuta Ocupacional, Técnico Administrativo, Técnicos de Enfermagem além dos Residentes Multiprofissionais, Profissionais em Treinamento em Serviço e estagiários de Serviço Social que fornecem um grande apoio ao tratamento.

\section{ALGUNS ASPECTOS ACERCA DO TEMA ÁLCOOL E OUTRAS DROGAS}

É importante salientar que estudos apontam que o consumo de álcool e outras drogas entre a população brasileira têm atingido níveis preocupantes, o que vem acarretando uma série de problemas relacionados a eles, onde se incluem os de ordem social e de saúde.

Uma pesquisa recente, realizada pelo Instituto Nacional de Políticas Públicas do Álcool e Outras Drogas (INPAD) da Universidade Federal de São Paulo (UNIFESP) em 2012, revelou um aumento do número de pessoas que se encontram com problemas relacionados ao uso indevido de álcool e outras drogas e que tem desenvolvido transtornos devido ao uso dessas substâncias. Questões de natureza sociais e legais também aparecem associadas às pessoas que estão envolvidas com o uso das mesmas.

O II Levantamento Nacional de Álcool e Drogas (II LENAD), realizado em 2012, estimou que $5,7 \%$ da população brasileira, cerca de 8 (oito) milhões de pessoas são dependentes do uso de álcool e alguma outra droga. O II LENAD também apontou que tem aumentado o número de pessoas que consomem álcool de forma nociva. Estima-se que 11,7 milhões de pessoas sejam dependentes de álcool no Brasil; quanto à diferenciação de ingestão de bebidas entre homens e mulheres, referente ao consumo com frequência, o estudo declara que houve um aumento de $29 \%$ para $39 \%$ entre as mulheres e de $56 \%$ para $64 \%$ entre os homens, em relação ao último levantamento realizado em 2006. Os dados também chamam a 


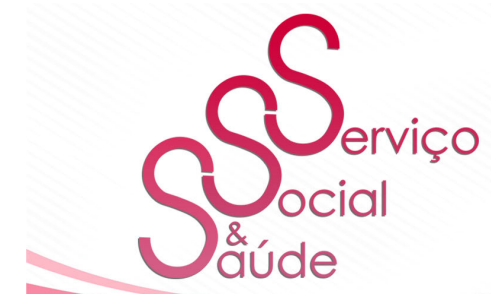

ISSN 2446-5992

(c) (i)(-)

doi: 10.20396/sss.v0i0.00000000

atenção quanto ao aumento do consumo de álcool em categoria binge, ou seja, "quando se consome 4 ou 5 doses de bebida no período de duas horas, uma vez ou mais por semana"(PIMENTEL, 2013), esta categoria refere-se a quantidade ingerida em um único episódio e constatam a elevação deste consumo de 36\% em 2006, para 49\% em 2012, em relação às mulheres e entre os homens de $51 \%$ para $66 \%$.

No Brasil e no mundo o uso, abuso e dependência de álcool e outras drogas tornou-se um problema de saúde pública, sobretudo, pelos altos índices de consumo que vem aumentando ao longo dos anos e ainda que os problemas com álcool e outras drogas estejam presentes em maior número entre os homens, percebe-se que há um aumento significativo no consumo também por mulheres. Além disso, as diferenças nos padrões de uso de substâncias entre homens e mulheres têm demonstrado diferenças de gênero em relação às consequências nas esferas social, psicológica e física.

\subsection{MULHERES E O USO DE DROGAS}

O uso, abuso e a dependência de álcool e outras drogas é maior entre os homens do que entre as mulheres, mas como dito anteriormente, o consumo entre elas vem aumentando e diante disso são consideradas grupos de usuários que possuem fatores de risco.

Dentre alguns problemas que tornam a dependência desse tipo de substâncias preocupante, tornando especificamente as mulheres um grupo de risco, estão os fatores farmacológicos, os quais explicam que o fato de as mulheres possuírem um volume corporal de água menor do que o dos homens ocasiona uma concentração maior de álcool no sangue do que as atingidas pelos homens que consomem a mesma quantidade. Outro fator problemático que merece destaque são as comorbidades psiquiátricas, as quais apresentam taxas maiores nas mulheres do que em homens, como transtornos do humor, de ansiedade, além de serem maiores os transtornos do pânico e os transtornos obsessivo-compulsivos. Há ainda os problemas de saúde, como câncer de mama, doenças cardiovasculares, doenças hepáticas e gástricas, as quais são mais elevadas em mulheres do que em homens (WOLLE E 


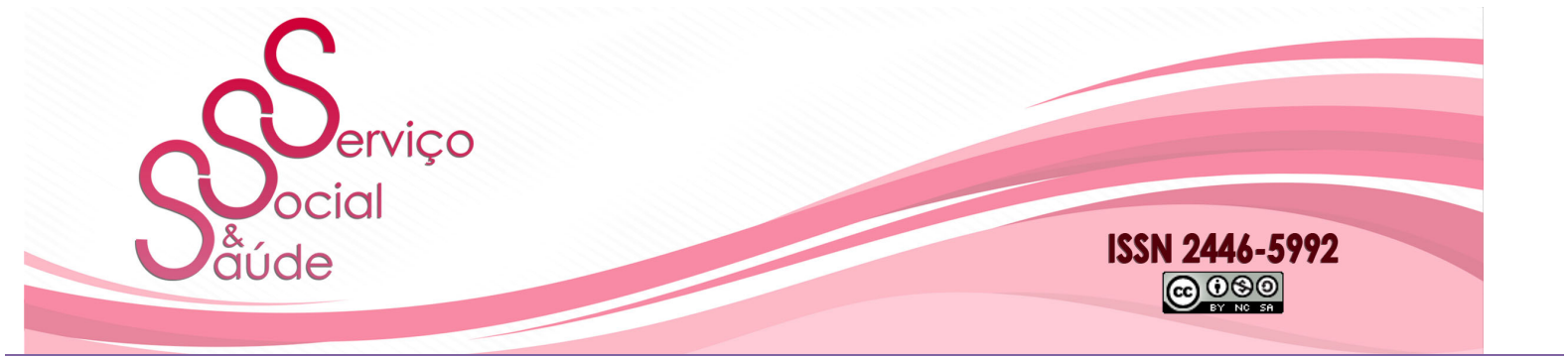

doi: 10.20396/sss.v0i0.00000000

ZILBERMAN, 2011).

O resultado da dependência feminina de drogas traz consequências maiores para as mulheres, tanto nos aspectos fisiológicos como nos fatores psicológicas, sobretudo, pela rotulação a que frequentemente são expostas: os valores morais e os padrões sociais estabelecidos para elas não condizem com a realidade de mulheres que estejam envolvidas com o uso de tais substâncias, afirmando a lógica enraizada na sociedade que é historicamente pautada nas relações excludentes de gênero (WOLLE E ZILBERMAN, 2011).

Ora, tempos atrás o uso de álcool entre as mulheres era restrito, pois era visto como incompatível com o papel doméstico tradicional desta, afetando assim seu comportamento social e suas responsabilidades (WOLLE E ZILBERMAN, 2011). Hoje, no entanto, ainda podemos notar a presença do julgamento moral e do preconceito sobre o abuso e a dependência de substâncias pelo público feminino e apesar dos números constatarem que elas se envolvem menos com a drogadição que os homens, as que consomem tais substâncias são frequentemente "rotuladas como negligentes e estão ligadas aos estereótipos de mulheres que são mais agressivas, tendendo à promiscuidade e que falharam ao tentar desempenhar o papel doméstico." (GALERA et al., 2005, p.5).

Desta maneira, com relação aos problemas que enfrentam relacionados ao uso destas substâncias, têm-se aqueles envolvendo a maternidade e o cuidado com os filhos. Historicamente foi atribuído a este segmento o papel maternal, de tal forma que este é visto como um instinto da mulher. De acordo com Olívio e Graczyk (2011, p. 4),

A maternidade, tão somente uma função biológica, é mitificada, sendo atravessada por aspectos sociais, cultural, políticos, ideológicos, econômicos, que servem à manutenção do Sistema de DominaçãoExploração das Mulheres (SAFFIOTI, 1987 e 2004), apresentando-se a partir de um cenário que envolve a representação da mulher-mãe sob as formas de perfeição dos sentimentos para com seus filhos.

Para estes autores, a construção da maternidade aponta-se como uma das formas de manutenção da Ordem Patriarcal de Gênero, na qual, as mulheres são subjugadas pela hegemonia masculina. E desta forma, o amor materno, é parte da natureza feminina, pois 


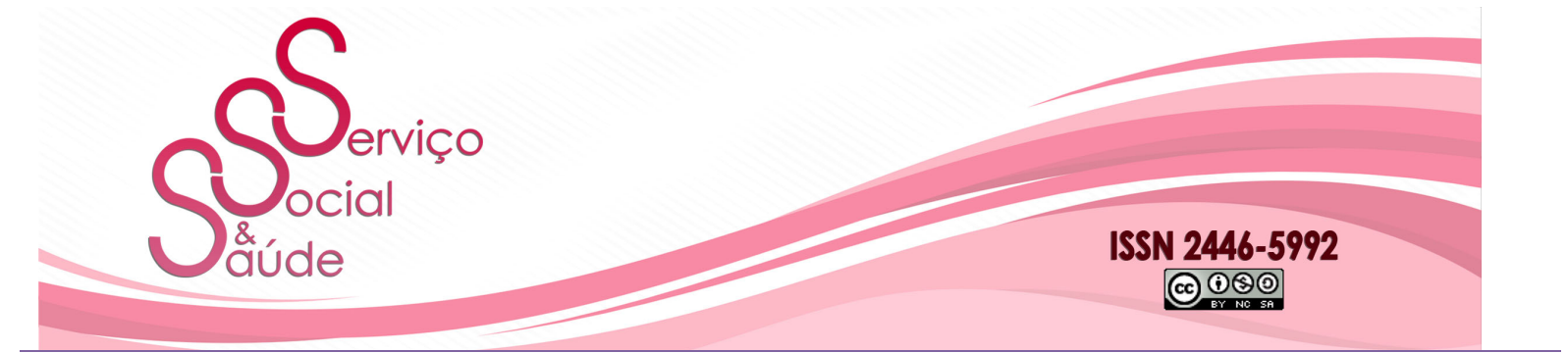

doi: 10.20396/sss.v0i0.00000000

[...] uma mulher é feita para ser mãe, e mais, uma boa mãe. Toda exceção à norma será necessariamente analisada em termos de exceções patológicas. A mãe indiferente é um desafio lançado à natureza, a anormal por excelência (OLIVIO; GRACZYK, 2011, p. 4).

Elenca-se para a mãe a função social do cuidado com os filhos e, em alguns casos, o uso de drogas pode contribuir para a "subversão da regra socialmente aceita do instinto materno" (OLIVIO; GRACZYK, 2011, p. 5). Desta forma, "o uso de drogas, com maior ênfase no crack, também corrobora com uma visão de culpabilização materna sobre o risco que representa a dependência química ao feto e ao recém-nascido" (OLIVIO E GRACZYK, 2011, p. 8). Além disso, para a mãe usuária de drogas, tem-se a punição por tal fato, recaindo na questão da destituição da guarda ou poder familiar.

E é nesse contexto que emerge um dos problemas sociais que vem se tornando crítico na cidade do Rio de Janeiro decorrentes do uso abusivo de álcool e outras drogas: a perda dos filhos por mulheres usuárias de drogas. Algumas medidas estão sendo tomadas em relação a estas mulheres: em algumas maternidades tem sido frequente o encaminhamento de bebês de usuárias de drogas, principalmente, com histórico de uso do crack, para a Vara da Infância e da Juventude e do Idoso (VIJI). E em resposta a este fato a VIJI tem optado por destituir a guarda dessas crianças de suas mães e em alguns casos, abrigá-las em instituições de acolhimento. Em pesquisa realizada pode-se perceber que esta realidade também vem ocorrendo em outras cidades do país, por exemplo, uma reportagem realizada por Bedinelli (2012) para a Folha de São Paulo aponta que já há um protocolo estabelecido para identificar a mãe usuária de droga em uma determinada maternidade de São Paulo.

Segundo a reportagem, a maior parte destas mulheres que tem seus partos realizados por esta maternidade, não saem com seus filhos de lá. A autora ainda afirma que $80 \%$ das vezes a Justiça manda essas crianças temporariamente para abrigos (BEDINELLI, 2012).

Em outra reportagem, dessa vez realizada pelo Jornal O Dia (2012), no Rio de Janeiro, observa-se que ocorre uma situação semelhante à de São Paulo: entre bebês que são afastados de suas famílias, o índice de pais usuários de entorpecentes, principalmente o crack, 


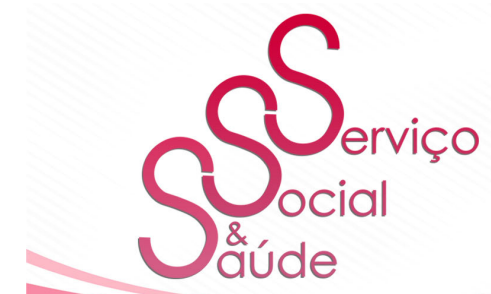

ISSN 2446-5992

(c) (i)(-)

doi: 10.20396/sss.v0i0.00000000

chega a 90\%. Nesta mesma reportagem a Promotora de Justiça da Infância e Juventude, Ana Cristina Macedo, afirma que "antes do crack, as ações de destituição do poder familiar eram motivadas por maus-tratos, violência física, sexual, agora isso tudo vem acoplado ao crack, pois a pessoa passa a ser agressiva e negligente por causa da droga" (JORNAL O DIA, 2012).

No entanto percebe-se que ação tomada pelo sistema judiciário vem sendo a de vincular essa perda da guarda a obrigatoriedade dessas mães de se tratarem do uso abusivo ou dependência das drogas.

\subsection{CONSIDERAÇÕES SOBRE A POLÍTICA DE DROGAS}

Os problemas que as pessoas enfrentam quanto ao uso nocivo e abusivo de álcool e outras drogas configuram hoje um problema de Saúde Pública, mas nem sempre foi assim. Segundo Valença (2013), vivemos num momento histórico em que gradativamente o trato com as drogas passa de uma perspectiva policial para uma perspectiva de saúde, com abordagem para cultura das drogas e cultura no sentido de que os usuários compartilham e constroem valores, rituais de uso e controles próprios, sendo assim, a perspectiva repressiva focava no indivíduo alienado pelo uso da substância e não considerava a sua cultura utilizando de medidas policialescas como enfrentamento para esta questão.

As políticas de drogas podem ser classificadas de acordo com o ponto de vista dos governantes de determinada sociedade, acredita-se que este problema desaparecerá eliminando-se a possibilidade de uso, desta forma, tem-se uma política de drogas amparada nos poderes Judiciário e Policial. Constituindo como prática repressiva a destruição das drogas, bem como, a criminalização dos envolvidos (ACSELRAD, 2004).

Percebe-se que a política de drogas no Brasil juntamente com suas práticas autoritárias firmadas na ditadura militar tornou-se um cenário de guerra às drogas e ao mesmo tempo um exercício de controle social das camadas mais pobres impondo restrições para a atenção equânime, integral e universal as pessoas usuárias de drogas, uma vez que são discriminados pelo seu contexto social (PASSOS;SOUZA, 2011). 


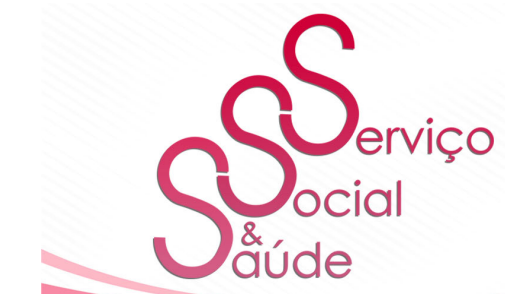

ISSN 2446-5992

(c) (i)(-)

doi: 10.20396/sss.v0i0.00000000

A intervenção do Estado diante do proibicionismo a certas drogas produziu dispositivos criminalizadores e punitivos sobre certos sujeitos e condutas relacionadas às drogas e entre os diversos discursos está o de proteção e segurança alegando-se que tais substâncias são nocivas a vida, desta maneira para preservar a vida e evitar a autodestruição iniciou-se uma guerra contra os vendedores e consumidores de drogas (LIMA; TAVARES, 2012). Neste contexto se insere a intervenção da justiça nos enfrentamentos desta questão lidando com os usuários de drogas de forma criminalizadora, inclusive em relação ao tratamento de saúde.

Portanto, é necessária uma articulação intersetorial para o enfrentamento das problemáticas que envolvem o consumo de drogas, como por exemplo, "parâmetros mais claros sobre quem é usuário abusivo, quem é dependente e como abordá-los, os diferentes setores sociais, agindo de forma descoordenada, tendem a potencializar danos que deveriam ajudar a reduzir" (VALENÇA, 2013, p.110). Tornando-se imprescindível também distinguir de forma mais clara as pessoas que consomem tais substâncias e possuem problemas referentes ao uso abusivo de drogas daquelas que realmente cometem delitos e crimes pela venda das substâncias.

Uma abordagem centrada na Saúde Pública ainda continua sendo realizada de forma fragmentária e autoritária. Sobre este aspecto, vale ressaltar que as ações no âmbito da saúde devem ser pautadas na integralidade, sobretudo, por este ser um dos princípios do Sistema Único de Saúde (SUS). Deste modo, é de extrema importância articular políticas públicas em que o sujeito seja visto em sua totalidade, mas que suas particularidades não sejam deixadas em segundo plano. No caso dos usuários de drogas ou que tem problemas relacionados ao seu uso, vemos algumas ações de saúde pautadas exclusivamente no uso das drogas, sendo por vezes outras dimensões esquecidas.

Em consonância com a Reforma Psiquiátrica, Valença (2013, p.117), afirma que "o usuário não deve ser visto como uma vítima passiva das substâncias utilizadas, mas sim, como um sujeito inserido em um contexto sociocultural específico". Uma das estratégias de reabilitação psicossocial preconizadas na Reforma Psiquiátrica é a inclusão social dos 


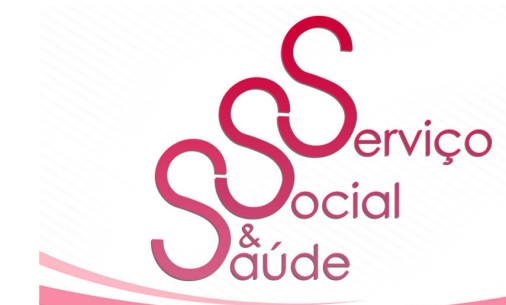

ISSN 2446-5992

(C) $10(0)$

doi: 10.20396/sss.v0i0.00000000

usuários para além dos desvios relacionados ao consumo das drogas.

Nesse sentido o autor enfatiza que:

[...] a política de direitos humanos e as estratégias de assistência social podem e devem favorecer uma resposta intersetorial, configurando uma rede de atenção eficaz para combater alguns aspectos da exclusão na qual está imerso o usuário e esta atenção deve ser integral, o que significa estabelecer conexões entre as redes públicas de saúde, de assistência social e jurídica, voltadas para a prevenção, atenção e tratamento dos usos e abusos de substâncias psicoativas (VALENÇA, 2013, p. 117).

Atualmente, a política que vem se consolidando como alternativa para o enfrentamento as questões relacionadas ao uso de álcool e outras drogas é a intitulada de Redução de Danos (RD), a qual tem como objetivo implantar atividades para a redução dos danos associados à ingestão das substâncias e o não compromisso com a eliminação do seu consumo. A proposta central é que, "não sendo possível a interrupção da utilização de drogas, ao menos que se minimizem seus danos junto ao usuário e à sociedade. Não se preocupa, portanto, única e exclusivamente com a erradicação do consumo de drogas da sociedade." (SERRA, 2007, p. 89).

A proposta da RD surgiu nos anos 80 trazendo como ação a troca de seringas utilizadas por usuários de drogas injetáveis, pois se constatou que o compartilhamento de tais objetos estava aumentando os índices de contaminação pelo HIV entre esta população. A primeira ação de RD utilizada no Brasil foi em 1989, em São Paulo, no município de Santos, em que a contaminação por compartilhamento de seringas chegava a 51\%. Em 1994 os dados epidemiológicos do Ministério da Saúde demonstravam que 25\% dos casos de AIDS no Brasil estavam associados ao uso indevido de drogas injetáveis, diante desta realidade foi necessário que a RD deixasse de ser uma ação pontual de um município e se tornasse uma ação nacional (PASSOS; SOUZA, 2011). O objetivo desta ação não era fazer com que os usuários deixassem de usar as drogas, mas de diminuir a transmissão do vírus pelo compartilhamento das seringas. Neste contexto, a RD tornou-se uma estratégia de prevenção, deixando de priorizar a ausência do consumo de drogas. 


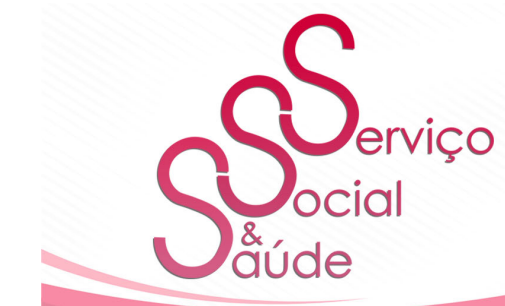

ISSN 2446-5992

(c) (i)(-)(2)

doi: 10.20396/sss.v0i0.00000000

As ações propostas pela RD visam à diminuição das consequências negativas da ingestão de drogas dirigidas as pessoas que não conseguem abandonar o uso ou não querem deixar de usá-las. Desta forma, a lógica da RD aparece como uma estratégia ao planejamento de propostas e ações preventivas para atenção a este público. E como forma de ampliar a diversificação de ofertas em saúde para usuários de drogas, as ações de RD, a partir de 2003, deixam de ser exclusivamente estratégias dos programas de DST/AIDS e se tornam uma estratégia norteadora da Política Nacional do Ministério da Saúde para a Atenção Integral a Usuários de Álcool e Outras Drogas e da Política de Saúde Mental (PASSOS E SOUZA, 2011).

A Associação Internacional de Redução de Danos (IHRA) define que

Redução de Danos se refere a políticas, programas e práticas que visam primeiramente reduzir as consequências adversas para a saúde, sociais e econômicas do uso de drogas lícitas e ilícitas, sem necessariamente reduzir o seu consumo. Redução de Danos beneficia pessoas que usam drogas, suas famílias e a comunidade (IHRA, 2010, p. 1).

É importante salientar que a perspectiva de RD se propõe a refletir sobre como os sujeitos se relacionam com as drogas, que lugar subjetivo e objetivo ocupam na vida de cada um consistindo, portanto, em pensar práticas em saúde que visem à singularidade dos sujeitos, valorizando a sua autonomia e tecendo planos de ação que objetivem sua qualidade de vida (BRASIL, 2014).

Pensando no campo da prevenção, as estratégias de redução de danos possuem alguns princípios básicos:

É uma alternativa de saúde pública aos modelos moral/ criminal e de doença do uso e da dependência de drogas;

Reconhece a abstinência como resultado ideal, mas aceita alternativas que reduzam os danos ao uso de substâncias psicoativas;

Surgiu principalmente como uma abordagem "de baixo para cima", baseada na defesa do dependente, em vez de uma política "cima para baixo", promovida pelos formuladores de políticas de drogas (BRASIL, 2014, p. 94). 


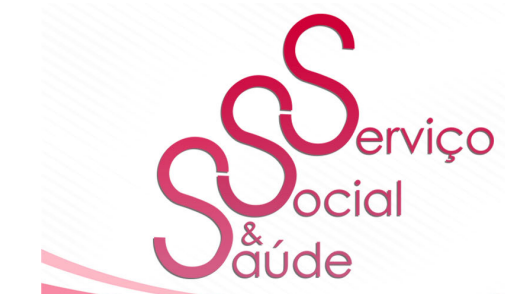

ISSN 2446-5992

(c) (i)(-)

doi: 10.20396/sss.v0i0.00000000

De acordo com a citação acima o fato de a RD ter sido construída coletivamente pelos usuários demonstraram que muitos usuários de drogas conseguiram abandonar ou mesmo reduzir o consumo porque experimentaram um contexto no qual se sentiam acolhidos e que se tornavam cogestores do seu próprio cuidado (PASSOS; SOUZA, 2011). Neste sentido podemos considerar que,

[...] a RD é um método construído pelos próprios usuários de drogas e que restitui, na contemporaneidade, um cuidado de si subversivo às regras de conduta coercitivas. Os usuários de drogas são corresponsáveis pela produção de saúde à medida que tomam para si a tarefa do cuidado (PASSOS; SOUZA, 2011, p. 161).

A RD torna-se, portanto, um método de cuidado em saúde acolhendo as pessoas que usam drogas como cidadãos de direitos e sujeitos políticos, levando-as serem protagonistas do seu próprio cuidado e do cuidado com o outro. A estratégia da RD demonstra outras linhas de cuidado em saúde para com estas questões que superam as ações centradas na repressão e estigmatização das pessoas que se relacionam com as drogas, colocando-os como sujeitos de si.

\section{LEVANTAMENTO, MÉTODO E ANÁLISE DOS DADOS}

Este estudo caracterizou-se como uma pesquisa qualitativa, pois conforme Minayo (2008), este tipo de abordagem reserva-se a um estudo da realidade que não pode ser quantificado preocupando-se com a qualidade das informações obtidas trabalhando com valores, crenças, significados, atitudes e opiniões.

Para o levantamento dos dados da pesquisa foi realizado uma busca em prontuários de usuárias que já realizavam tratamento na unidade e que possuíam registro sobre a perda total ou parcial da guarda ou que ainda estavam enfrentando problemas judiciais envolvendo esta questão e que foram encaminhadas para tratamento na UNIPRAD por algum órgão do Sistema Judiciário.

O levantamento compreendeu o período de Janeiro de 2013 a Janeiro de 2014 em que identificamos 111 mulheres que deram entrada no Serviço para tratamento do uso abusivo ou 


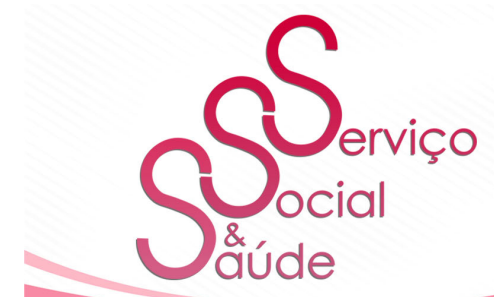

ISSN 2446-5992

(c) (i)(3) (2)

doi: 10.20396/sss.v0i0.00000000

dependência, no entanto, dessas mulheres 60 prontuários correspondiam a familiares que acompanhavam o tratamento de seus filhos, esposos e irmãos; em 16 prontuários não encontramos nenhum relato profissional de atendimento realizado o que dificultou a classificação destes atendimentos; 8 prontuários não foram encontrados no setor; 21 prontuários correspondiam a mulheres que realizavam algum tratamento relacionado ao uso das substâncias e apenas 6 prontuários relatavam história da perda da guarda parcial ou total dos filhos por conta do uso das drogas.

Para a captação dos dados optamos por realizar a entrevista semiestruturada, pois de acordo com Minayo (2008, p.64): “as entrevistas semiestruturadas combinam perguntas fechadas e abertas, em que o entrevistado tem a possibilidade de discorrer sobre o tema em questão sem se prender à indagação formulada". Optou-se por este tipo de entrevista, principalmente, pelo fato de permitir apreender de modo mais aprofundado as questões de motivação, atitudes e sentimentos transmitidos por tais mulheres.

Para nortear a entrevista foi criado um roteiro com cinco perguntas e com intuito de captar de forma mais fidedigna e detalhada os depoimentos, todas as entrevistas foram gravadas em aparelho MP3, que foram posteriormente transcritas e analisadas. Para a realização da entrevista, inicialmente foi estabelecido contato telefônico com as usuárias para convidá-las a participarem da pesquisa e deste modo agendado dia e horário para a coleta dos dados. No entanto, deve-se frisar que algumas usuárias não foram encontradas mediante a mudança de telefone ou informações incompletas nos prontuários e outras não quiseram participar da pesquisa, sendo assim, necessitamos ampliar o período da pesquisa e começamos a captar as mulheres que davam entrada no serviço pela primeira vez com esta problemática e aceitavam participar da pesquisa. Ao todo foram entrevistadas cinco mulheres. Desta forma, as usuárias que concordavam com a pesquisa assinaram o termo de consentimento - que explicavam as proposições, riscos e benefícios da pesquisa - e responderam as perguntas formuladas para a entrevista. Todas as entrevistas garantiram o anonimato e o sigilo das entrevistadas.

Para análise dos dados foi utilizado o método da análise de conteúdo (AC), segundo o 


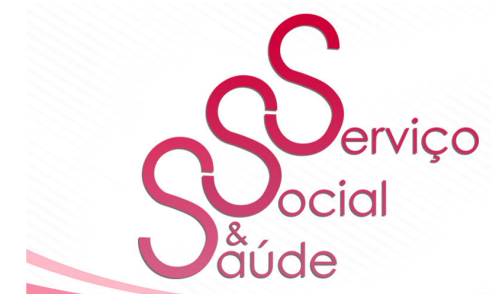

ISSN 2446-5992

(c) (i)(-)

doi: 10.20396/sss.v0i0.00000000

referencial teórico de Laurence Bardin, pois é considerada uma técnica de pesquisa que trabalha com a palavra, permitindo de forma prática e objetiva produzir inferências do conteúdo da comunicação de um texto replicáveis ao seu contexto social (CAREGNATO; MUTTI, 2006).

Com base nas entrevistas realizadas, foram criadas quatro categorias de análise, tendo em vista os objetivos definidos para a pesquisa: analisar o quanto a perda da guarda provisória ou definitiva dos filhos de mulheres usuárias de álcool e outras drogas interferem no seu tratamento de saúde nesta área; identificar a rede de acolhimento e suporte às mulheres-mães que tem seus filhos abrigados por enfrentar problemas com álcool e outras drogas; apresentar os aspectos legais que levam as mulheres-mães a perderem a guarda total ou provisória de seus filhos; identificar quais são e como estão sendo aplicadas as políticas públicas para o enfrentamento e recuperação das mulheres usuárias de álcool e outras drogas. As categorias criadas foram: ocasião da perda da guarda, intervenção da justiça no tratamento, fatores emocionais ao perder a guarda e identificação da rede de assistência.

\subsection{OCASIÃO DA PERDA DA GUARDA}

Esta categoria buscou analisar o momento em que se deu a perda da guarda efetivamente, ou seja, de que modo isso aconteceu pela visão das entrevistadas para identificarmos sobre quais aspectos legais essas mulheres perderam a guarda. Procurou-se nesta categoria colher a história inicial que culminou na perda da guarda. Nesta categoria pode-se perceber com a fala das entrevistadas algumas ações criminalistas e policialescas que circundam o usuário de drogas, como ações de controle social que foram exercidas por algumas instituições de saúde e dentro da própria família envolvendo questões de gênero. Em análise das entrevistas, três participantes relataram que a Maternidade onde realizaram o parto as encaminharam para a VIJI, destacando-se:

Foi por causa da droga, só isso só [...] isso tem há muito tempo que eu usei, 


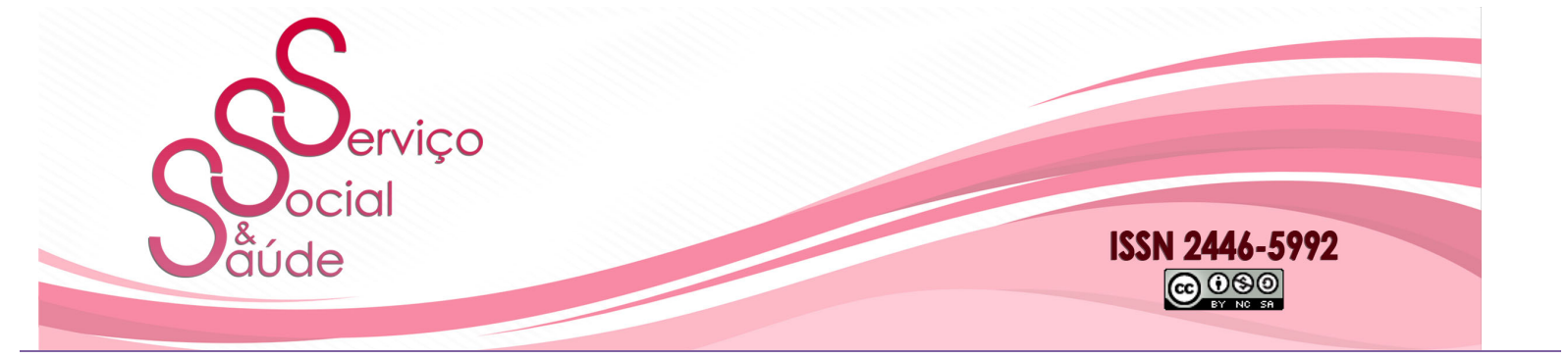

doi: 10.20396/sss.v0i0.00000000

só foi porque eu fiquei com medo de prejudicar minha filha, aí eu falei Entrevistada 2

[...] eu fui ter o meu filho e tinha usado a droga [...] aí chegando lá (Maternidade) tem um formulário que a gente tem que preencher e nesse formulário eu falei que tinha usado a droga, aí a assistente social do hospital me encaminhou para o juizado - Entrevistada 3

[...] tava usando, na gravidez, o crack [...]. Na gravidez deu reagente o uso de drogas e eu não menti nem pra assistente social nem pra psicóloga que trabalha lá na Maternidade X, aí a Maternidade X me encaminhou pro juizado de menores - Entrevistada 5

Outro contexto que se destacou quanto a esta categoria foi à questão da denúncia pelos próprios familiares dessas mulheres, em ambas as entrevistas o denunciante foi o pai da criança. Essa questão afirma a relação de gênero e a moralidade que se tem sobre as mulheres enquanto usuárias de álcool e outras drogas perante a sociedade. Uma vez que mulheres usuárias destas substâncias são historicamente rotuladas como negligentes ou fora do padrão para desempenhar seus papéis domésticos e de cuidadora dos filhos. Nesta categoria pode-se perceber que os familiares entram com a intervenção da justiça mediante a denúncia por causa da proteção das crianças,

[...] acontece que meu marido me pegou e falou que se eu continuasse desse jeito vou levar lá (VIJI)... aí ele pegou e levou a criança lá (VIJI)Entrevistada 1

[...] foi uma denúncia pro Conselho Tutelar do próprio pai do meu filho que eu quis usar droga aí eu passei a noite toda usando, mas com meu filho em casa $[. .$.$] eu o deixei por alguns minutos e fui num bar perto da esquina pra$ comprar cigarro e pra ver se eu arrumava mais alguma coisa, aí foi onde que ele chegou e meu filho tava sozinho aí denunciou, eu fui chamada e fui pra Vara da Infância, onde foi decretada que eu tinha perdido a guarda Entrevistada 4

Conforme Tomizawa e Moreira (2006), o poder familiar tem como objetivo a proteção da criança e do adolescente do nascimento até a maioridade e deve ser entendido como um instituto que estabelece aos pais um conjunto de direitos e deveres quanto à criação e formação de seus filhos. Dessa forma, quando os pais ou um deles não cumprem o dever de proteger seus filhos, isto é, violam seus direitos, há a intervenção do Estado com a destituição 


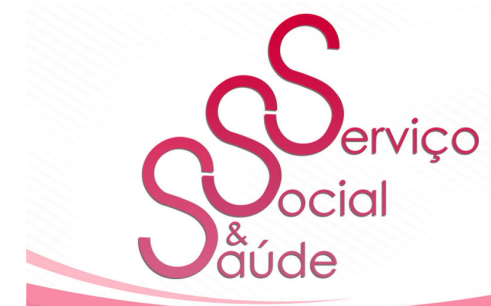

ISSN 2446-5992

(c) (i)(-)(2)

doi: $10.20396 /$ sss.v0i0.00000000

do poder familiar de forma a garantir os interesses das crianças ou adolescentes envolvidos. Deste modo, a destituição do poder familiar torna-se uma medida aplicada aos pais ou responsáveis, também encontradas no texto do Estatuto da Criança e do Adolescente - Art. 129 São medidas aplicáveis aos pais ou responsável: VIII. perda da guarda; IX. destituição da tutela; X. suspensão ou destituição do pátrio poder (BRASIL, 1990).

Outra questão apontada no Estatuto da Criança e do Adolescente refere-se ao Direito à Convivência Familiar e Comunitária, disposto no art.19:

Toda criança ou adolescente tem direito a ser criado e educado no seio da sua família e, excepcionalmente, em família substituta, assegurada a convivência familiar e comunitária, em ambiente livre da presença de pessoas dependentes de substâncias entorpecentes (BRASIL, 1990, destaques do autor).

O direito à convivência familiar e comunitária é um direito conquistado em terras brasileiras e seu principal objetivo é impedir que crianças e adolescentes tenham as instituições de acolhimento como estratégias naturalizada de cuidado, uma vez que, o Brasil corresponde internamente no que diz respeito a proteção infanto-juvenil totalmente contrário à institucionalização (BÁRBARA, 2012).

Segundo Rizzini et al. (2007), no ano de 1990, firma-se uma posição internacional claramente oposta à institucionalização de crianças e os novos referenciais legislativos enfatizam o direito da criança em permanecer em um contexto familiar e comunitário e ao poder público cabe à garantia deste direito.

É importante destacar que,

[...] a medida de acolhimento institucional deve ser aplicada excepcionalmente e ser provisória, pois o entendimento é que o regular desenvolvimento do segmento infanto-juvenil só ocorre quando há convivência familiar e comunitária, e não com isolamento, privação e segregação (BARBARA, 2012, p. 121).

No entanto, identificaram-se nesta pesquisa que algumas mulheres tiveram seus filhos afastados do seu convívio e abrigados em instituições de acolhimento, outras perderam a 


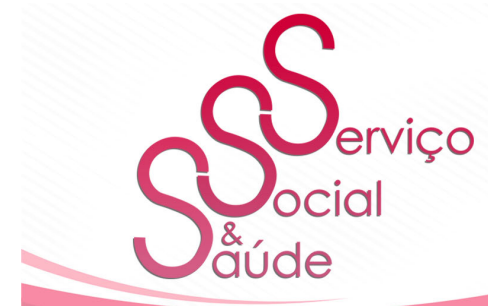

ISSN 2446-5992

(c) (i)(-)(2)

doi: 10.20396/sss.v0i0.00000000

guarda para seus familiares e conseguiram apenas o direito a visitação. Desta forma, percebemos as contradições na assistência prestada a estas mulheres no primeiro momento enfrentado por esta problemática quanto ao que é previsto no próprio Estatuto da Criança e do Adolescente em relação ao convívio familiar e também quanto ao afastamento dessas crianças de suas mães para instituições de acolhimento como uma primeira medida de proteção adotada, quando na verdade, o afastamento das crianças deve ser o último a ser realizado, quando se esgotarem todas as possibilidades de enfrentamento dessas situações.

A medida tomada pela VIJI torna-se cautelar em relação às crianças, mas ao mesmo tempo autoritária com as mães e divergem dos princípios e objetivos preconizados pela Política Nacional de Álcool e Drogas e o cuidado em Saúde Mental que ao invés de reduzir os danos, os potencializa com segregação e ruptura do convívio com seus filhos. Deve-se enfatizar que os casos encaminhados pelas Maternidades também corroboraram para a situação dessas mulheres mães, pois encaminharam os casos para a VIJI muitas vezes sem uma avaliação criteriosa sobre as condições efetivas de essas mulheres exercerem a maternidade.

\subsection{INTERVENÇÃO DA JUSTIÇA NO TRATAMENTO}

Falar de cuidado em Saúde Mental requer perpassar os antecedentes históricos do tratamento oferecido para estas questões, incluindo, a drogadição. Sobretudo para entendermos de que forma o Judiciário vem tratando esta temática, e sob qual visão vem pautando suas ações.

Antes da Reforma Psiquiátrica, a psiquiatria pautava-se no modelo biomédico para o cuidado em saúde mental tratando os problemas mentais como causas orgânicas oferecendo tratamento com ênfase na visão biológica, centrado nas doenças e contribuindo para a exclusão e afastamento social dos sujeitos acometidos por estes problemas, pois os usuários eram retirados do convívio social e encarcerados em hospitais psiquiátricos. Entre os usuários que apresentavam algum problema relacionado ao campo da saúde mental estavam os 


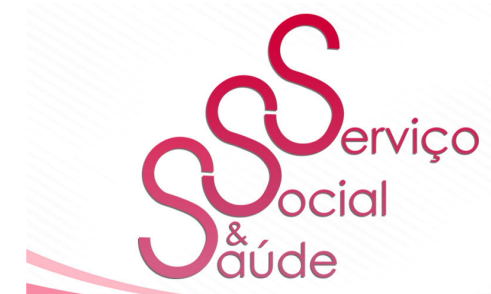

ISSN 2446-5992

(c) (i)(-)

doi: 10.20396/sss.v0i0.00000000

mendigos, leprosos, tuberculosos e também os usuários de drogas.

Aos usuários de drogas a assistência prestada eram encaminhamentos às instituições psiquiátricas com a finalidade de retirá-los do convívio social para que abandonassem o uso e para que se enquadrassem nos padrões sociais vigentes a época, tratando os indivíduos que enfrentavam problemas relacionados às drogas com questões morais e de disciplinamentos recaindo para o sujeito a criminalização pela sua condição sendo muitas vezes considerados desviantes da sociedade. Historicamente a

[...] articulação entre criminologia e psiquiatria no Brasil vem de um diálogo iniciado na segunda metade do século XIX, numa interlocução direta com o Direito Penal. É dentro deste jogo de poder que o usuário de drogas ora se vê perante a criminologia, ora diante do poder da psiquiatria (PASSOS; SOUZA, 2009, p.157).

E é nesse sentido que ainda percebem-se as ações do Judiciário. Trazendo esta reflexão para os dias atuais e para a emblemática deste estudo observa-se que as intervenções da justiça em alguns tratamentos de saúde ainda seguem a lógica punitiva, como no caso das mulheres que perderam a guarda de seus filhos por usarem drogas.

Esta categoria procurou levantar de que forma a intervenção da justiça interferiu no tratamento para as drogas. Pode-se observar que inicialmente a palavra interferência foi absorvida pelas entrevistadas como algo negativo, que impedisse a realização do tratamento e as mesmas responderam que não havia interferência, mas em seguida pontuavam de que modo essa intervenção contribuiu para o tratamento. Desta forma, podem-se desvelar algumas ações de controle social e padronização nas vidas desses sujeitos, tais como:

[...] acho que mudou um pouco sim [...] levantar cedo, ir trabalhar [...] aí é bom pra eu aprender, pra ficar mais ligeiro pra não fazer mais coisa errada Entrevistada 1

Não, interferir não né, ela me ajudou pra mim fazer né, que até então eu não me dava conta né, caiu a ficha - Entrevistada 3

Com certeza, eu acredito que sem tratamento jamais eles iam dar pra mim (a guarda), porque como que eles vão acreditar numa pessoa que não busca ajuda? Sozinha acho que ninguém consegue não... - Entrevistada 4 


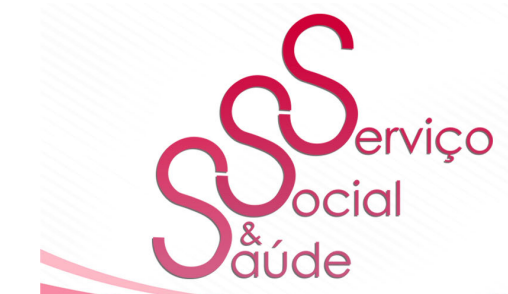

ISSN 2446-5992

(c) (i)(-)

doi: 10.20396/sss.v0i0.00000000

[...] não, por que fez assim eu começar a fazer a escola de pais Entrevistada 5

Ao analisar esta categoria percebe-se que a intervenção judicial nessas mulheres produziu efeitos que as obrigassem a se vincular a uma instituição de saúde como um dos requisitos para reaver a guarda. Não me parece que haja uma real preocupação com o curso do tratamento efetivamente. A ordem judicial para realização do tratamento funciona coercitivamente para controlar e vigiar esta população.

No entanto, este modelo assistencial pautado na vigilância dos usuários e na punição pelas suas condutas de forma a apresentarem características morais tomou novas configurações com o movimento da Reforma Psiquiátrica. Uma vez que a atual política de saúde mental brasileira teve suas bases fundadas nas lutas de familiares, usuários e profissionais para mudar este modelo desde a década de 1980. O movimento foi impulsionado para que houvesse mudanças, sobretudo em relação aos direitos humanos destes usuários, para que o novo modelo de atenção preconizasse a desinstitucionalização dos sujeitos dos manicômios e que a atenção aos portadores de problemas mentais tivesse como objetivo o exercício de sua cidadania (BRASIL, 2013).

Deve-se ressaltar ainda que há claramente uma questão de pobreza associada à conduta da VIJI, uma vez, que as mulheres entrevistadas possuíam baixa escolaridade e renda precária, algumas desempregadas e outras no mundo do subemprego. Bárbara (2012) reforça este argumento ao dizer que, "são as mulheres as mais vulneráveis a não reunirem as condições de cuidado e sustento da prole e situa a destituição familiar no debate sobre a feminização da pobreza" (BÁRBARA, 2012, p. 125).

Outra questão a ser enfatizada aqui com esta intervenção da Justiça é a ausência de um projeto terapêutico singular para o tratamento destas mulheres percebendo a falta de articulação da VIJI com as questões que envolvem a saúde e constatando um atendimento frio prestado às mesmas ao oferecerem apenas encaminhamentos para as instituições de saúde, como requisito para reaver a guarda se vincularem a um tratamento especializado para o uso das drogas. 


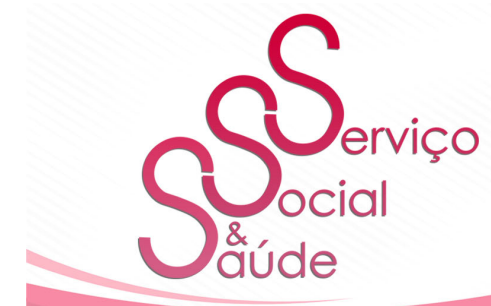

ISSN 2446-5992

(C) $\odot \otimes(0)$

doi: 10.20396/sss.v0i0.00000000

\subsection{FATORES EMOCIONAIS AO PERDER A GUARDA}

O processo saúde-doença inclui desde a dimensão coletiva, uma vez que a saúde dos sujeitos é influenciada pelo contexto no qual estão inseridos, como a dimensão individual, pois o sofrimento e o adoecimento são experiências singulares e pessoais, ainda que partilhados com outras pessoas, como os profissionais. Porém, nem todos os profissionais estão preparados para lidar com o sofrimento, pois a discussão sobre sofrimento e adoecimento implica em compreender o processo saúde-doença para além das suas causas, considerando, portanto, as relações entre os sujeitos e os determinantes das condições gerais de saúde. A Organização Mundial da Saúde - OMS define saúde como "o completo estado de bem-estar físico, mental e social, e não simplesmente a ausência de enfermidade”, nesse sentido a saúde também é resultado de um processo de produção social e suas influências sobre ela (LACERDA; VALLA, 2008).

Nesse sentido, esta categoria buscou analisar os sentimentos e os fatores emocionais que surgiram nestas mulheres quando perderam a guarda de seus filhos. Muito se fala na proteção das crianças cujas mães envolvem-se com drogas, erroneamente associando a figura da mulher-mãe-usuária àquele negligente, que põe seus filhos em risco, generalizando as situações. Conforme, Bárbara (2012),

[...] a dependência química associada a fatores socioeconômicos retira as condições do exercício da maternidade de forma responsável e segura, mas isso não significa que as mulheres mães usuárias de drogas não tenham o desejo e não tentem maternar seus filhos (BÁRBARA, 2012, p. 123).

Não se deve negar que algumas mães, assim como, também seus pais podem colocar seus filhos em risco por causa do uso das substâncias, mas este não pode ser o único fator para a tomada desta decisão e nem tampouco a pobreza. Também não deve ser negado, que ao ocorrer esta situação, as mães são carregadas de sofrimento e culpa e isto pode ser observado nas entrevistas, quando indagadas de como se sentiram com tal situação:

[...] ahh eu me senti chateada, queria até morrer, se eu perder minha filha eu 


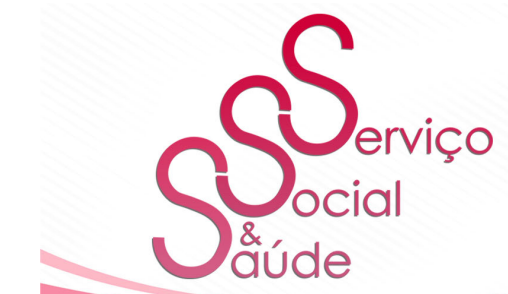

ISSN 2446-5992

(c) (i)(2) (2)

doi: 10.20396/sss.v0i0.00000000

morro - Entrevistada 1

[...] eu me senti humilhada, eu fiquei triste de ter perdido ela, dela ter ficado no abrigo, me culpo por isso (choro) - Entrevistada 2

[...] muito mal, foi a pior coisa que aconteceu na minha vida, eu durmo pensando e acordo pensando, é um tormento na minha vida isso (choro) Entrevistada 3

[...] péssima, chorei muito, fiquei triste - Entrevistada 4Os sentimentos expressos por estas mulheres demonstraram a fragilidade que elas enfrentam ao estarem sendo duplamente punidas pelo envolvimento com as drogas. Pois no tocante a dependência de drogas o enfrentamento delas são superdimensionados "quando o usuário é mulher-mãe justamente pela cobrança social do amor, dedicação e proteção integral à prole" (BÁRBARA, 2012, p. 123). Mas diante disso percebe-se que estas mulheres trazem consigo um grande sofrimento pela perda e "não são mães desnaturadas, mas estão em um nível de sofrimento impensável e que não conseguem sair disso" (BÁRBARA, 2012, p.123). Desta forma merecem cuidado em suas questões que já são carregadas de preconceitos e acabam interferindo negativamente em seu tratamento.

O fato de associarem as mães usuárias de drogas às mulheres negligentes no cuidado com seus filhos, passa pelo problema comum aos usuários de drogas que é a questão do estigma e dos estereótipos criados para esta população. É comum os usuários de drogas carregarem marcas impostas pela sociedade que os tornam marginalizados e excluídos de alguns contextos sociais. A estigmatização ocorre quando se atribui "rótulos" e "estereótipos" negativos a determinados comportamentos (BRASIL, 2014). Tal situação influencia direta ou indiretamente a condição de saúde da pessoa estigmatizada, provocando diversas consequências, inclusive o agravamento da situação e até mesmo o não reconhecimento da doença, como se percebe na entrevista: [...] porque nunca uma mãe vai perder uma filha assim a troco de nada, porque eu não me sinto nenhuma viciada - Entrevistada 2 (destaques do autor).

A questão do consumo é envolvida em significações marginais que acabam dificultando o reconhecimento da dependência e acaba gerando e reforçando preconceitos e segregações em relação aos usuários e entre eles mesmos e acabam não propiciando uma 


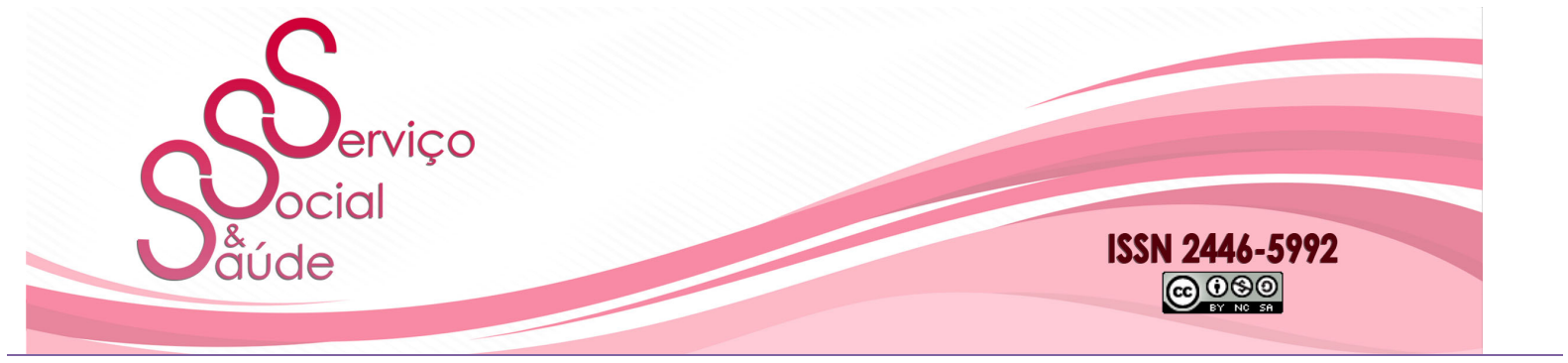

doi: 10.20396/sss.v0i0.00000000

sensibilização para a mudança do comportamento em relação às drogas (PRATTA; SANTOS, 2009).

Contrário às mulheres que não reconhecem a dependência de drogas para realizarem o tratamento, outra questão que deve ser enfatizada aqui é em relação às mulheres que foram obrigadas a se vincular ao serviço de saúde para tratamento das drogas, como requisito para reaver a guarda de seus filhos, sem necessariamente apresentarem problemas com o uso abusivo e nocivo de drogas e foram rotuladas como dependentes e encaminhadas para o tratamento. Algumas das mulheres entrevistadas para esta pesquisa, em análise dos seus prontuários, não eram consideradas pelos profissionais que as acompanhavam como pessoas dependentes de drogas, pois algumas delas relataram que o uso de drogas foi um único episódio de suas vidas e que desencadeou esta problemática ao mencionarem na Maternidade o uso durante algum período da gestação.

\subsection{IDENTIFICAÇÃO DA REDE DE ASSISTÊNCIA}

Esta categoria procurou analisar de que forma as usuárias entrevistadas receberam apoio da rede assistencial no momento em que perderam a guarda de seus filhos e qual foi o apoio prestado às mesmas. Pode-se perceber com a questão que as mulheres não identificaram o que é oferecido pela VIJI como suporte e nem identificam uma rede de cuidados em seu território. Ao mesmo tempo em que as mulheres responderam que não receberam nenhum tipo de apoio, elas identificaram alguns equipamentos da rede de assistência para qual foram encaminhadas. Desta forma, pode-se entender o tipo de encaminhamento e atendimento que essas mulheres receberam neste momento pela VIJI.

Para Lacerda e Valla (2008) o sofrimento pode ser desencadeado pela perda dos papéis sociais e pelos relacionamentos significativos e podem trazer danos físicos, morais, emocionais e sociais para o indivíduo. Sendo assim ressaltamos a importância do cuidado integral no processo de sofrimento destes indivíduos: “Cuidar é, portanto, uma atitude interativa que inclui o envolvimento e o relacionamento entre as partes, compreendendo acolhimento, escuta do sujeito, respeito pelo seu sofrimento e pelas histórias de vida." 


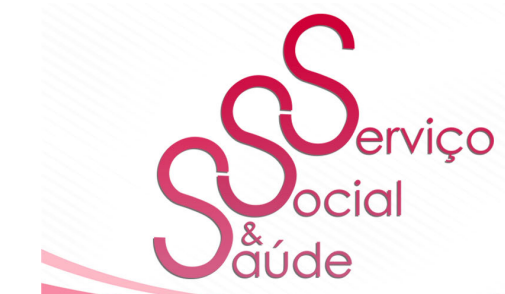

ISSN 2446-5992

(c) (i)(-)

doi: 10.20396/sss.v0i0.00000000

(LACERDA E VALLA, 2008, p. 97).

Dessa forma, o cuidado é entendido como uma dimensão da integralidade permeando as práticas da saúde, mas não podem se restringir às competências e tarefas meramente técnicas e devem ser realizadas de forma interdisciplinar e articuladas com os profissionais em rede, de forma que todos participem do cuidado e fortaleçam as redes de apoio. Desse modo, pode-se identificar os dispositivos assistenciais para os quais as mulheres foram encaminhadas, mas o processo que se iniciou na VIJI deveria também estar implicado no tratamento e comprometimento com estas mulheres, no entanto, as usuárias não identificam este apoio ao destacarem que não receberam nenhum apoio da VIJI, somente encaminhamentos:

Não! Só me encaminharam, falaram que eu tinha que fazer o tratamento e ir lá ver a menina no abrigo, só isso. - Entrevistada 1

Não, só me encaminharam pra cá e pra mim fazer o Bolsa Família lá no CRAS, só isso - Entrevistada 2

[...] me encaminhou pra cá (UNIPRAD) e pra reunião de pais lá mesmo no Juizado - Entrevistada 3

Não, só aqui mesmo e lá naquele que eu pego o remédio, no CPRJ Entrevistada 4

Não, só me encaminharam pro CRAS e mandaram frequentar a Escola de Pais toda semana e mandaram eu vim aqui nas consultas, só - Entrevistada 5

Como uma dimensão do cuidado afirma-se a potencialidade do acolhimento institucional como primeiro passo para escuta dessas mulheres, sobretudo, porque iniciaram um processo delicado e de sofrimento ao perderem a guarda de seus filhos. $\mathrm{O}$ acolhimento torna-se fundamental nas instituições, pois ele oferece um espaço adequado de escuta aos usuários e seus familiares de suas angústias, sofrimentos e histórias de vida, também auxilia na formação do vínculo entre profissional e usuário para estabelecer a linha de cuidado e o projeto terapêutico singular a ser construído com aquele indivíduo. É de extrema importância que os usuários se sintam tranquilos e seguros para expressarem suas aflições, dúvidas e 


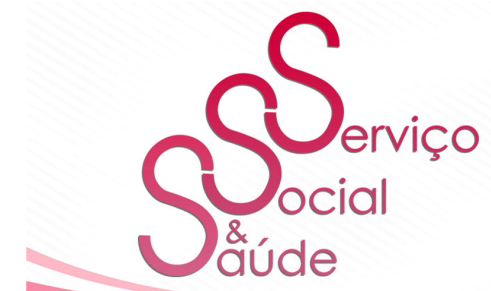

ISSN 2446-5992

(c) (i)(-)

doi: 10.20396/sss.v0i0.00000000

medos. Dentro desta visão percebeu-se nas falas das entrevistas que não foram devidamente acolhidas neste momento de suas vidas.

\section{CONSIDERAÇÕES FINAIS}

A partir da reflexão acima apresentada e com os dados obtidos por esta pesquisa, é possível concluir que discutir os problemas relacionados ao uso de álcool e outras drogas na atualidade é discutir a questão do processo saúde/doença dentro das novas configurações das políticas públicas que visam práticas integrais de cuidado com a saúde, na perspectiva da totalidade do sujeito.

É necessário refletir as práticas e medidas adotadas atualmente para o manejo com situações que envolvam o uso de substâncias psicoativas e os indivíduos afetados para que as situações sejam tratadas de acordo com a singularidade de cada ocasião, para que não se generalize situações e padronize ações como o caso das mulheres que perdem a guarda de seus filhos sem ao menos terem colocados os mesmos em risco por conta do uso das drogas. Não desconsidera-se aqui que em alguns casos as medidas protetivas de afastamentos das crianças do convívio de suas genitoras tornam-se necessárias devido aos reais riscos apresentados, mas não pode-se generalizar que mães usuárias de drogas são negligentes por natureza e não tem a capacidade de maternar seus filhos.

Pode-se perceber que as mulheres mães usuárias de álcool e outras drogas que tiveram destituídos o poder familiar foram duplamente violentadas, pois foram criminalizadas pelo uso das substâncias e por terem o direito a convivência com seus filhos negado. Tem-se ainda a questão da pobreza associada aos fatores que contribuíram para o desenvolvimento da problemática apresentada, pois todas as mulheres entrevistadas encontravam-se em situação de risco social e tiveram sua situação socioeconômica atrelada as intervenções do Estado.

$\mathrm{O}$ acolhimento que essas mulheres relataram ao passar por este momento também deve ser revisto, pois as mesmas não se sentiram acolhidas neste processo e enfatizaram que 


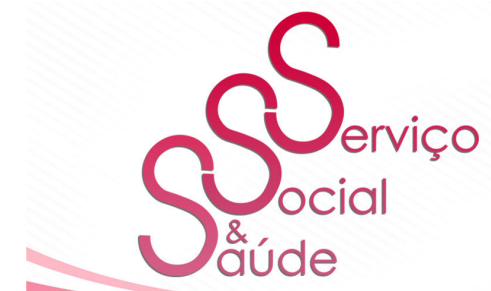

\section{ISSN 2446-5992}

(c) (i)(2)

doi: 10.20396/sss.v0i0.00000000

receberam apenas encaminhamentos, produzindo quase que um descaso neste momento de vulnerabilidade que se encontraram, descolados de uma prática integral no cuidado. $\mathrm{O}$ sofrimento trazido por elas também é pauta para discussão, pois em alguns casos, o dano produzido por estas ações aumentaram os danos emocionais ao invés de reduzirem como preconiza a política pública do Ministério da Saúde para os usuários de drogas.

Percebe-se também que o sistema Judiciário ainda possui uma visão fechada em relação ao enfrentamento de problemas que envolvem o uso de drogas sendo relacionadas às práticas de vigilância e punição que antecedem a Reforma Psiquiátrica produzindo estigmas e estereótipos sobre estas mulheres. E que as medidas tomadas para a obrigatoriedade do tratamento de saúde dessas mulheres é contrário à lógica do tratamento atualmente adotada pela saúde mental pautada nos princípios da política de redução de danos. Para finalizar podese perceber que as políticas públicas aplicadas nesta emblemática, ainda, reproduzem sua historicidade, são fragmentárias e focais e endossam o agir autoritário e controlador do Estado contra alguns segmentos da sociedade como os pobres, as mulheres e os usuários de drogas.

\section{Recebido dezembro 2017 - Aprovado abril 2018}

\section{REFERÊNCIAS}

ACSELRAD, G. Políticas de Drogas e Cultura de Resistência. Disponível em:

HTTP://www.ffnt.org.to/aa/img upload/52db53d37ec3594c9a13faaeef9c48a44/Gilbertadoc/

Acesso em: Fevereiro de 2014.

BÁRBARA, D. do V. S. Algumas reflexões sobre a destituição do poder familiar de mulheres mães pobres e a adoção de seus filhos. Revista Praia Vermelha. Rio de Janeiro. V.22 n 1. p.119-131. Jul./dez. 2012.

BRASIL. Presidência da República. Estatuto da Criança e do Adolescente. Lei no 8.069, de 13 de julho de 1990. Disponível em: http://www.planalto.gov.br/ccivil_03/leis/18069.htm Acesso em: fevereiro de 2014. 


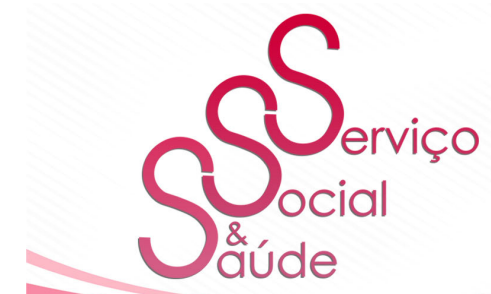

ISSN 2446-5992

(c) (i)(-)(2)

doi: 10.20396/sss.v0i0.00000000

BRASIL. Ministério da Saúde. Secretaria Executiva. Coordenação Nacional de DST/Aids. A Política do Ministério da Saúde para atenção integral a usuários de álcool e outras drogas. Brasília: Ministério da Saúde, 2003. Disponível em: http://bvsms.saude.gov.br/bvs/publicacoes/pns alcool drogas.pdf Acesso em: Janeiro de 2015

BRASIL. Ministério da Saúde. Secretaria de Atenção à Saúde. Saúde Mental. Cadernos de Atenção Básica, n 34. Brasília - DF. 2013. Disponível em:

http://189.28.128.100/dab/docs/portaldab/publicacoes/caderno 34.pdf Acesso: dez. 2014. BRASIL. Ministério da Justiça. Secretaria Nacional de Políticas sobre Drogas. Atenção integral na rede de saúde: módulo 5. - 5ed. Brasília, 2014.

BRASIL. Lei no 8.080, de 19 de setembro de 1990. Brasília: Ministério da Saúde, 1990. BRASIL. Lei $\mathbf{n}^{\mathbf{0}} \mathbf{\text { 10.216}}$, de 6 de abril de 2001. Dispõe sobre a proteção e os direitos das pessoas portadoras de transtornos mentais e redireciona o modelo assistencial em Saúde Mental. In: BRASIL. Ministério da Saúde. Legislação em saúde mental 1990-2004. 5. ed. ampliada. Brasília: Ministério da Saúde, 2004a

BEDINELLI, T. Em maternidade para viciada em crack, mãe tem alta, mas bebê fica. Folha de São Paulo. São Paulo, 10 dez.2012. Disponível em: http://www1.folha.uol.com.br/cotidiano/2012/12/1198702-em-maternidade-para-viciada-emcrack-mae-tem-alta-mas-bebe-fica.shtml Acesso em: Janeiro de 2014.

CAREGNATO, R. C. A. MUTTI, R. Pesquisa qualitativa: análise de discurso versus análise de conteúdo. Texto Contexto Enfermagem, Florianópolis, 2006. Out./dez., p. 679-684.

Disponivel em: www.scielo.org Acessado em: Maio de 2014.

GALERA, S. A. F. ROLDAN, M. C. B.; O’BRIEN, B. Mulheres Vivendo no Contexto de Drogas (e violência) - Papel Maternal. Revista Latino-americana de Enfermagem. N 13. Nov./dez., 2005. Disponível em: http://www.scielo.br/pdf/rlae/v13nspe2/pt_v13nspe2a07.pdf Acessado em: Janeiro de 2014. 


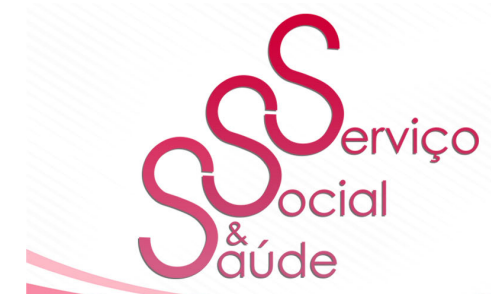

ISSN 2446-5992

(c) (i)(-)(2)

doi: 10.20396/sss.v0i0.00000000

IRHA. O que é Redução de Danos? Uma posição oficial da Associação Internacional de Redução de Danos, Londres, Grã Bretanha, 2010.p. 1-5.

JORNAL O DIA, Crack já é a principal responsável pela perda da guarda de crianças no Rio, Rio de Janeiro, 2012. Disponível em: http://odia.ig.com.br/portal/rio/crackj\%C3\%A1-\%C3\%A9-a-principal-respons\%C3\%A1vel-pela-perda-da-guarda-decrian\%C3\%A7as-no-rio-1.465652 Acesso em: Janeiro de 2014.

LACERDA, A. VALLA, V. V. As práticas terapêuticas de cuidado integral à saúde como proposta para aliviar o sofrimento. In: PINHEIRO, R. MATTOS, R. A. de. Cuidado - as fronteiras da integralidade. Rio de Janeiro, CEPESC/UERJ, ABRASCO, 2008.

LARANJEIRA, R ; MADRUGA, C. S. PINSKY, I.; CAETANO, R. MITSUHIRO, S. II Levantamento Nacional de Álcool e Drogas. Disponível em: http://inpad.org.br/wpcontent/uploads/2013/04/LENAD ALCOOL ResultadosPreliminares.pdf. Acesso em: fevereiro de 2014.

LIMA, R.de C. C; TAVARES, P. Desafios recentes às políticas sociais brasileiras sobre as drogas: enfrentamento ao crack e proibicionismo. Argumentum, Vitória - ES. v. 4, n.2, p.623, jul/dez 2012.

MINAYO, M. C. de S. Pesquisa Social: Teoria, Método e Criatividade. 27ª Ed. Petrópolis, RJ: Vozes, 2008.

OLIVIO, M. C.; GRACZYK, R. C. Mulheres usuárias de crack e maternidade: breves considerações.In: Anais II Simpósio Gênero e Políticas Públicas ISSN2177-8248 Universidade Estadual de Londrina, 18 e 19 de agosto de 2011.p.1-11.

PASSOS, E. H.; SOUZA, T. P. Redução de Danos e saúde pública: construções alternativas à política global de "guerra as drogas". Psicologia \& Sociedade. N.23, p.154-162, 2011.

Disponível em: http://www.scielo.br/scielo.php?pid=S0102-

71822011000100017\&script=sci_arttext Acesso em: Dezembro de 2014 


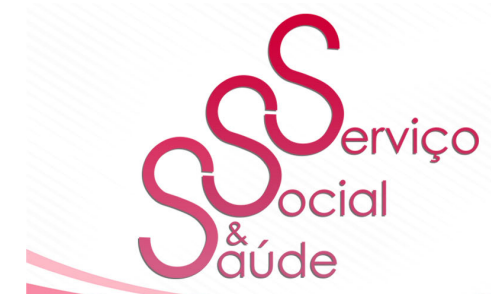

\section{ISSN 2446-5992}

(c) (i)(2)

doi: 10.20396/sss.v0i0.00000000

PIMENTEL, J. II Levantamento Nacional de Álcool e Drogas mostra o consumo de álcool crescente e desigual pela população brasileira. Determinantes sociais da saúde portal e observatório sobre iniquidades em saúde. [Internet]. Rio de Janeiro: Portal DSS Brasil; 2013 Jun 13. Disponível em: http://dssbr.org/site/2013/06/ii-levantamento-nacional-dealcool-e-drogas-mostra-o-consumo-de-alcool-crescente-e-desigual-pela-populacao-brasileira/ PRATTA, E. M. M.; SANTOS, M. A. dos. O processo saúde-doença e a dependência química: interfaces e evolução. Psicologia: Teoria e Pesquisa. Vol. 25, n.2, p.203-211, abr./jun, 2009.

RIZINI, I. et al. Acolhendo crianças e adolescentes: experiências de promoção do direito à convivência familiar e comunitária no Brasil. São Paulo: Cortez, $2^{\circ}$. Ed; Brasília: UNICEF; CIESPI; Rio de Janeiro: PUC Rio, 2007.

SERRA, Á. S. V.“Esqueceram de mim”: Políticas públicas de atenção em saúde em relação ao uso, abuso e dependência de álcool e outras drogas para crianças e adolescentes.

Dissertação de Mestrado. Rio de Janeiro: UFRJ, 2007.

TOMIZAWA, G.; MOREIRA, J. A. Destituição do poder familiar: punição ou garantia de direitos? Disponivel em:

http://www.animaopet.com.br/pdf/anima6/Destituicao_do poder_familiar.pdf Acesso: Jan. 2014.

VALENÇA, T. Possíveis aproximações entre a cultura do uso de crack e uma política pública. In: ÑUNES, M. E; TAVARES, L. A; MACRAE, E. Drogas: Clínica e Cultura. CETAD/UFBA. Salvador, 2013, p. 105-134.

WOLLE, C. de C.; ZILBERMAN, M. Mulheres. In: DIEHL, Alessandra ET AL. Dependência Química: prevenção, tratamento e políticas públicas. Porto Alegre: Artmed, 2011, p. 375-382. 


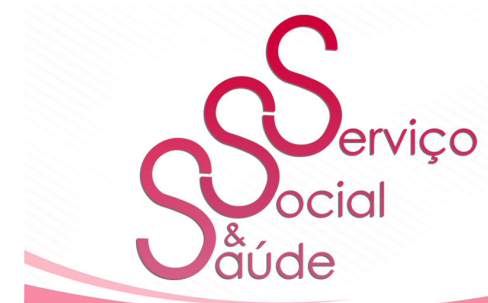

ISSN 2446-5992

(C) (1) (-)

doi: 10.20396/sss.v0i0.00000000 